Article

\title{
Optimal Design of High-Frequency Induction Heating Apparatus for Wafer Cleaning Equipment Using Superheated Steam
}

\author{
Sang Min Park ${ }^{1}$, , Eunsu Jang ${ }^{2}$, Joon Sung Park ${ }^{1}{ }^{\circledR}$, Jin-Hong Kim ${ }^{1}$, Jun-Hyuk Choi ${ }^{1}$ \\ and Byoung Kuk Lee ${ }^{2, *}$ \\ 1 Intelligent Mechatronics Research Center, Korea Electronics Technology Institute (KETI), \\ Bucheon 14502, Korea; smpark@keti.re.kr (S.M.P.); parkjs@keti.re.kr (J.S.P.); kimjinhong@keti.re.kr (J.-H.K.); \\ cjh@keti.re.kr (J.-H.C.) \\ 2 Department of Electrical and Computer Engineering, Sungkyunkwan University (SKKU), \\ Suwon 16419, Korea; jespro@skku.edu \\ * Correspondence: bkleeskku@skku.edu; Tel.: +82-31-299-4581
}

Received: 19 October 2020; Accepted: 22 November 2020; Published: 25 November 2020

\begin{abstract}
In this study, wafer cleaning equipment was designed and fabricated using the induction heating (IH) method and a short-time superheated steam (SHS) generation process. To prevent problems arising from the presence of particulate matter in the fluid flow region, pure grade 2 titanium (Ti) R50400 was used in the wafer cleaning equipment for heating objects via induction. The Ti load was designed and manufactured with a specific shape, along with the resonant network, to efficiently generate high-temperature steam by increasing the residence time of the fluid in the heating object. The IH performance of various shapes of heating objects made of Ti was analyzed and the results were compared. In addition, the heat capacity required to generate SHS was mathematically calculated and analyzed. The SHS heating performance was verified by conducting experiments using the designed $2.2 \mathrm{~kW}$ wafer cleaning equipment. The performance of the proposed pure Ti-based SHS generation system was found to be satisfactory, and SHS with a temperature higher than $200{ }^{\circ} \mathrm{C}$ was generated within $10 \mathrm{~s}$ using this system.
\end{abstract}

Keywords: induction heating (IH); superheated steam (SHS); LCL resonant network; cleaning equipment; titanium (Ti); high frequency; wafer cleaning

\section{Introduction}

The cleaning process is the most important task in improving the yield and reliability of the manufacturing process. With advancements in the fabrication technology of liquid crystal displays (LCDs), the size of the mother glass (MG) is continually being increased, and the cleaning processes employed during fabrication are becoming increasingly vital. In particular, the process of depositing a transistor layer on an MG substrate that is employed to fabricate thin film transistors (TFTs) requires a cleaning process for the MG substrate, as shown in Figure 1. Contaminants such as residual organic materials and particulates are present on the surface of work pieces such as semiconductor wafers and the MG of LCDs [1,2]. Cleaning processes for removing such organic materials and particles are indispensable because these substances can generate defects in manufactured products; various cleaning methods have been proposed in this regard [3-5]. A wet cleaning method, known as vapor phase cleaning (VPC), is widely used because it is inexpensive and has proven technology. However, wet cleaning methods that involve the use of strong acids are regulated due to environmental pollution and safety issues $[6,7]$. A dry cleaning method has been developed to compensate for the disadvantages 
of the wet cleaning methods. This dry cleaning method includes processes such as ultrasonic cleaning, excimer ultraviolet (EUV) cleaning, and plasma cleaning [8-10]. However, the disadvantage of dry cleaning equipment is that it is difficult to construct and is large in size $[9,11]$.

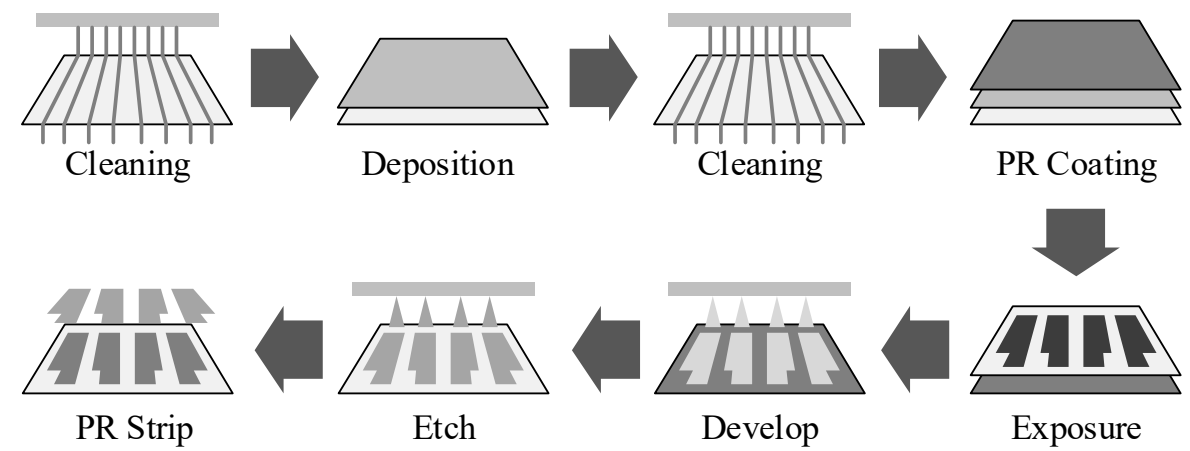

Figure 1. Overview of the thin film transistor (TFT)-liquid crystal display (LCD) manufacturing process.

Recently, cleaning equipment that is eco-friendly and has excellent washing capability has been developed using superheated steam (SHS) at a high temperature and pressure [12]. The SHS cleaning equipment uses a heater to heat water contained in a tank to generate SHS at temperatures above $200^{\circ} \mathrm{C}$; then, the SHS is sprayed onto the MG and wafer to clean them. The conventional equipment utilized for generating SHS heats water directly using a heating wire. In this method, the power used to generate SHS is significant and the process is time consuming. Furthermore, in such methods, the preparation time for the cleaning process is long and the precise temperature control capability required for cleaning may be lacking.

In this study, considering the need for a short-time SHS generation process, cleaning equipment that can uniformly heat the heating object with high efficiency was designed by applying the induction heating $(\mathrm{IH})$ method. Common metals, such as cast iron, cannot be used as heating objects in the TFT-LCD cleaning process because of particle problems in the fluid flow area $[13,14]$. Thus, pure grade 2 titanium (Ti) R50400 was used as the heating object for IH cleaning and IH joule heating of the Ti load. Additionally, the Ti load was designed and manufactured in a specific shape, along with the resonant network, to efficiently generate high-temperature steam by increasing the residence time of the fluid in the heating object. Moreover, several heating objects were designed and manufactured using pure $\mathrm{Ti}$, and the $\mathrm{IH}$ performances of the heating objects with respect to the shape were experimentally compared. The SHS heating performance of the proposed cleaning system was verified via experiments using the designed $2.2 \mathrm{~kW}$ wafer cleaning equipment.

\section{Analysis of Specific Enthalpy Steam and Titanium Characterization}

In this section, the heat capacity for generating SHS is mathematically calculated, and the characteristics of the non-magnetic Ti load are analyzed. The power capacity of the cleaning equipment was selected based on the results of this analysis; in addition, the cleaning equipment is manufactured by new power plasma (NPP) Corporation in Korea.

\subsection{Calculation of Steam Heat Capacity}

SHS is high-temperature steam that is further heated using saturated steam generated from boiling water, as shown in Figure 2. Because SHS is a gas in a low-oxygen state in which only water $\left(\mathrm{H}_{2} \mathrm{O}\right)$ molecules exist, oxidation of the heated object does not occur, and the risk of fire or explosion is reduced $[15,16]$. Furthermore, SHS has a strong drying ability because it possesses high thermal conductivity. However, as the specific heat capacity of water is relatively higher than that of other substances, the temperature change is slow, as shown in Figure 2a [17-19]. Furthermore, it can be observed from Figure $2 b$ that higher temperatures need to be considered because the boiling point 
varies with the pressure in the cleaning equipment. Thus, it is time consuming to generate SHS above a temperature of $200{ }^{\circ} \mathrm{C}$ by rapidly heating water at a room temperature of $25^{\circ} \mathrm{C}$. Therefore, in this study, the saturated steam was prepared by preheating the water contained in a water supply tank using a heating wire, as illustrated in Figure 3. By applying this method to the steam cleaning process, SHS can be generated within a short time, and thus processing time can be reduced.
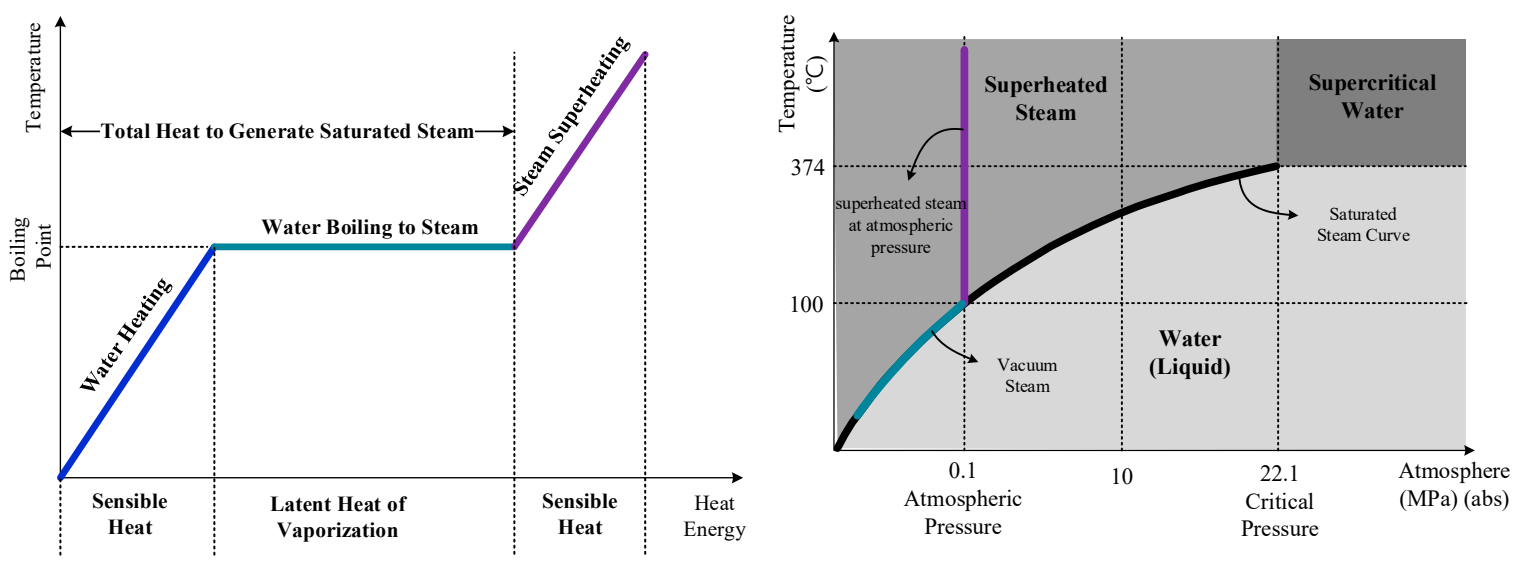

Figure 2. Temperature relationship of water and steam.

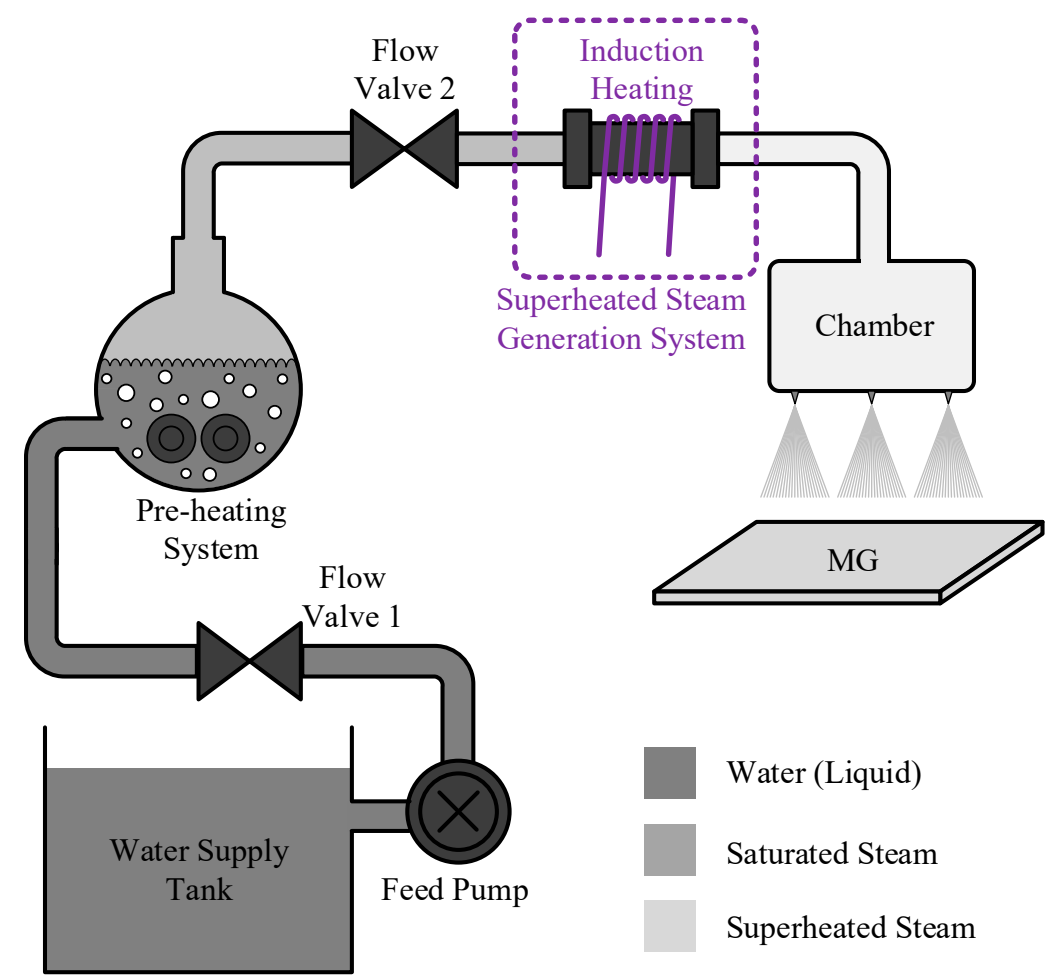

Figure 3. Steam heating structure of the cleaning equipment. MG, mother glass.

The heat capacity required to heat the saturated steam entering the Ti load for generating SHS should be calculated to determine the power capacity of IH-type cleaning equipment. The expression for the heat capacity required to heat saturated steam to generate SHS is given as follows:

$$
Q_{\text {heat }}=m \cdot c \cdot \Delta T
$$


where $m, c$, and $\Delta T$ are the mass of the steam, specific heat capacity, and temperature variation, respectively [20]. $m$ can be calculated as follows:

$$
m=\gamma \cdot C M H, \quad(\gamma=\rho g)
$$

where $\gamma$ and $\mathrm{CMH}$ are the specific weight and cubic meter per hour, respectively. In Equation (2), $\mathrm{CMH}$ is equal to the flow rate, and $\gamma$ can be calculated by multiplying $\rho$ by $g$ (acceleration due to gravity) $[20,21]$. To generate SHS using the IH process, the pressure and volume of the gas should be considered. These can be calculated using an ideal gas equation (IGE), based on the Boyle-Charles's law, as follows:

$$
\begin{gathered}
P V=n R T \\
V=22.414 \times \frac{t^{\circ} \mathrm{C}+K}{K} \\
\rho=P \times \frac{M}{V}
\end{gathered}
$$

Using Equation (4), the volume of 1 mole of gas at $1 \mathrm{~atm}$ can be derived from the absolute temperature and instantaneous temperature of the gas. The density is calculated using volume, molecular mass, and pressure, as expressed in Equation (5). $C_{p}$, the specific heat capacity of steam at constant pressure, is calculated using the steam table [22,23]. Therefore, the heat quantity $Q_{\text {heat }}$ calculated using Equation (1) is the absolute heat quantity required for heating, and it can be converted into electric power energy for heating the steam by selecting the target temperature and heating time.

\subsection{Design and Implementation of the Heating Object for Rapid Induction Heating}

In the TFT-LCD and wafer cleaning equipment that uses the IH method, SHS is generated by heating the heating object after building up a flow path of the fluid inside the shape of the heating object. However, as shown in Table 1, pure grade 2 Ti R50400, which was used as the heating object in this study, has a low relative permeability and electrical resistivity compared to other magnetic metal materials [23-25]. Thus, a high switching frequency and high current were needed to increase the IH joule heat of Ti.

Table 1. Comparison of titanium and stainless steel.

\begin{tabular}{ccc}
\hline Parameter & Grade 2 Ti & Stainless Steel (SUS304) \\
\hline Resistivity $[\rho(\mu \Omega \mathrm{cm})]$ & 55 & 72 \\
Relative Permeability $\left[\mu_{\mathrm{s}}\right]$ & 1.00018 & 2.291 \\
Thermal Conductivity $\left[\mathrm{Wm}^{-1} \mathrm{~K}^{-1}\right]$ & 0.041 & 0.039 \\
\hline
\end{tabular}

The length of the heating object through which the fluid flowed was limited to less than $10 \mathrm{~cm}$ to minimize the volume of the cleaning equipment and the transfer path of the steam. In addition, because foreign matter affects fluid purity, the inner surface of the heating object, which constituted the fluid path, was not welded. Therefore, a heating object with a structure in which the inner fluid path was made of pure Ti was designed such that the fluid could stay within a limited length for a long time. A typical heating object, shown in Figure 4, has advantages such as ease of manufacture and simplicity of structure. However, it requires sufficient preheating before the fluid flows due to the fact that the outer surface is heated first in IH and the fluid stay time is short [26-28].

Figure 5 shows the $\mathrm{IH}$ principle and eddy current distribution when heating a cylindrical heating object. As described above, only the outline was heated based on the results of the simulation of the thermal distribution of a cylindrical heating object. Therefore, considering the characteristics of $\mathrm{IH}$, a shape was proposed in which the fluid path was located within the spiral shape on the outer surface of the heating object, as depicted in Figure 6. In particular, the proposed heating object could secure a much longer fluid movement path in the same length compared to a conventional heating object. 
Figure 7a shows a heating cylinder made of Ti that was manufactured based on the proposed geometry. The Ti cylinder was designed, with a spiral groove on the outer surface, to be surrounded by a Ti pipe, which constituted the fluid movement path. The inside surface was safe from particulate matter because only the exterior of the cylinder, which was outside the fluid path, was welded. Moreover, while the total length of the shape was $10 \mathrm{~cm}$, the length of the fluid path and the stay time could be increased by changing the shape of the structure. Another advantage of this structure was that the outer surface was heated first in IH. Figure $7 \mathrm{~b}$ shows the results of a Ti load wound on a 1/4-in copper tubing coil. A general litz wire could not be used because a large current with a high frequency flows through the coil [29]. Therefore, water cooling was performed by flowing distilled water into the coil using a copper tubing coil.

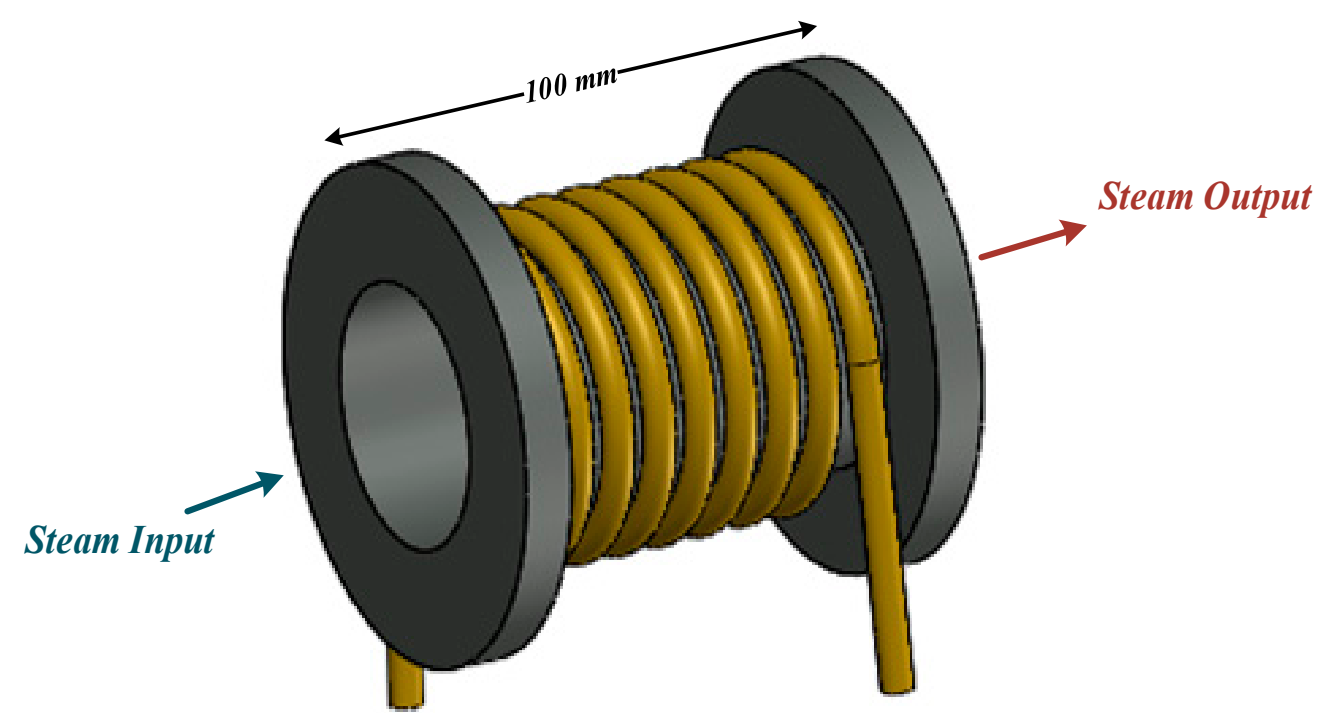

Figure 4. Structure of heating objects typically employed in the cleaning process.

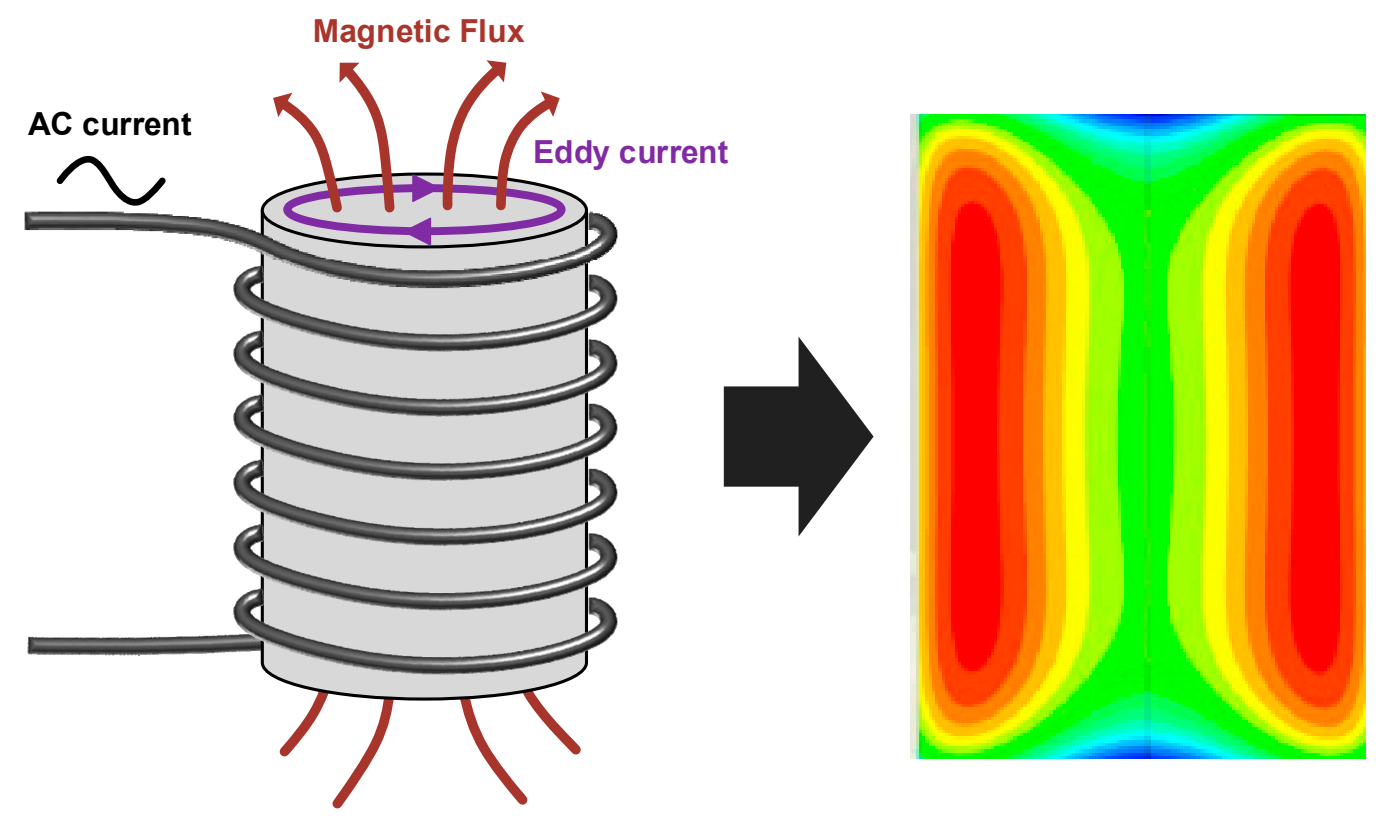

Figure 5. Principle and characteristics of induction heating. 


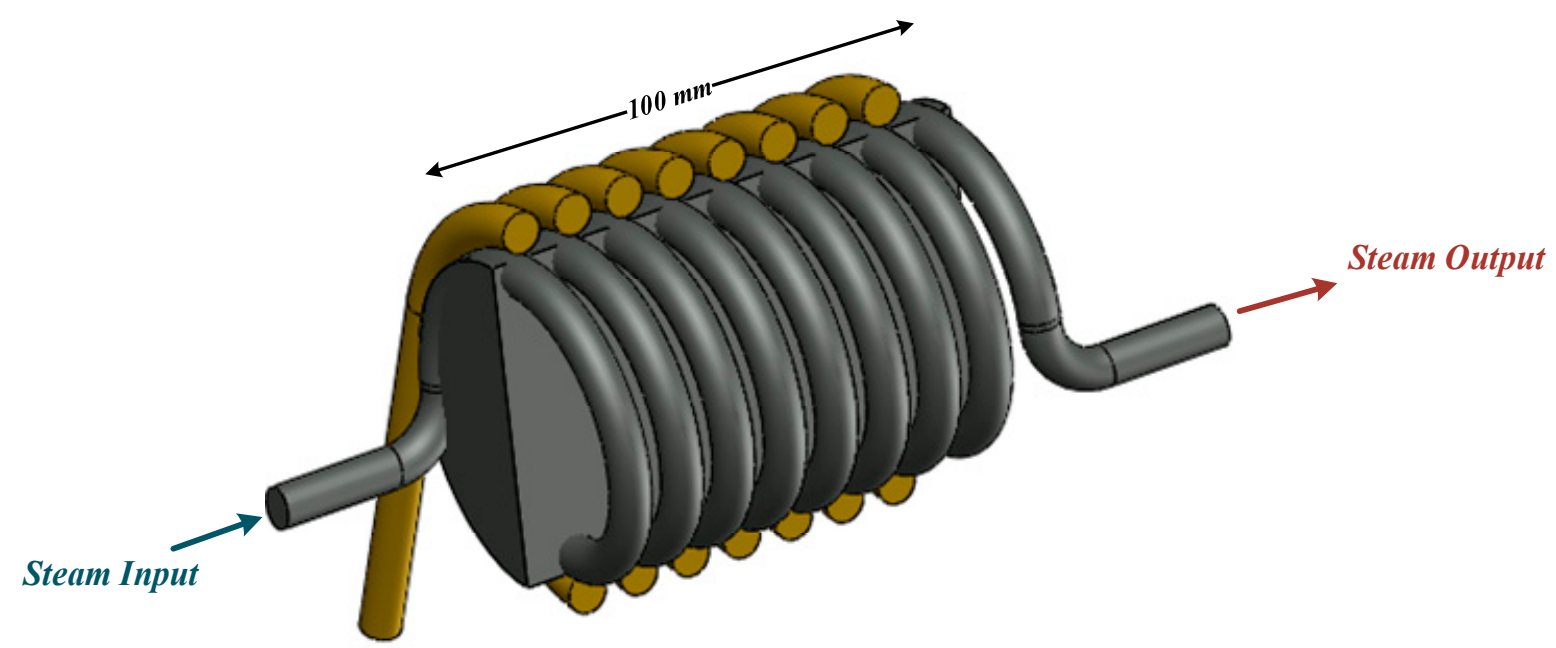

Figure 6. Shape of the proposed heating object.

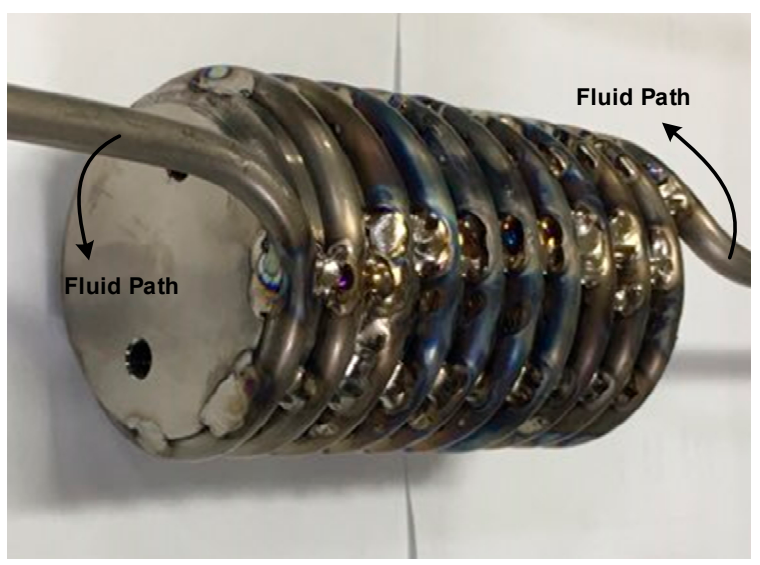

(a) Heating object fabricated using $\mathrm{Ti}$

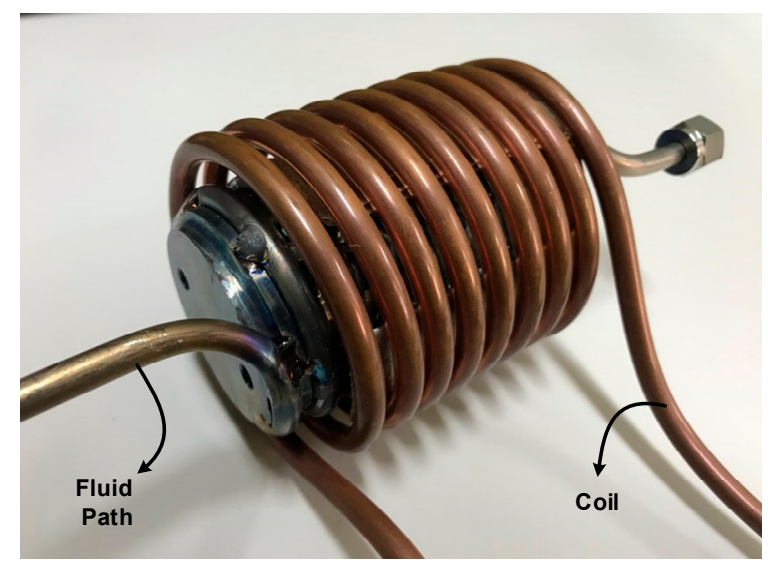

(b) Ti load

Figure 7. Proposed titanium (Ti) load structure of the cleaning equipment.

\subsection{Parameter Analysis of the Titanium Load}

In this section, the parameter values of the implemented Ti load are analyzed. The operating frequency and power capacity of the cleaning equipment were selected based on the analyzed parameters. The principle of the IH technology is based on Faraday's law of electromagnetic induction, which states that a magnetic flux is generated when a high-frequency current flows through a coil. This magnetic flux induces an eddy current on the surface of the heating object and generates joule heat, owing to the skin effect $[30,31]$. Most of this joule heat is distributed within the skin depth $(\delta)$, which is a significant factor in determining the inverter operating frequency. The $\delta$ can be calculated as follows:

$$
\delta=\sqrt{\frac{1}{4 \pi^{2} \times 10^{-7}}} \times \sqrt{\frac{\rho}{\mu_{r} f}}
$$

where $\rho, \mu_{r}$, and $f$ are the resistivity of the material, relative permeability, and frequency of the current flowing in the coil, respectively. This $\delta$ is determined from the point when the skin depth of the high-frequency current becomes $1 / e$ (approximately 0.368 ) times the current density of the surface, and most of the current and power distributions belong to the skin depth from the surface to $\delta$, as shown in Figure 8; therefore, in the IH system, it is advantageous to heat the surface of a heating object under high-frequency operating conditions, since all eddy currents are concentrated on the $\delta$ of the surface. Therefore, to increase the low resistivity value of the Ti load, the inverter switching frequency should be increased. Generally, the IH system can be represented using a transformer equivalent model in 
which the coil and load are the primary and secondary sides, respectively [32-34]. This transformer equivalent model can be simplified using a series connection circuit of the equivalent inductance $L_{e q}$ and equivalent resistance $R_{e q}$, as shown in Figure 9. The mathematically analyzed $R_{e q}$ is given as follows:

$$
R_{e q}=r+\frac{(\omega M)^{2} \cdot R_{L}}{R_{L}^{2}+\left(\omega L_{2}\right)^{2}}=r+A^{2} R_{L}
$$

and $L_{e q}$ is calculated as follows:

$$
L_{e q}=L_{1}-\frac{(\omega M)^{2} \cdot L_{2}}{R_{L}^{2}+\left(\omega L_{2}\right)^{2}}=L_{1}-A^{2} L_{2}
$$

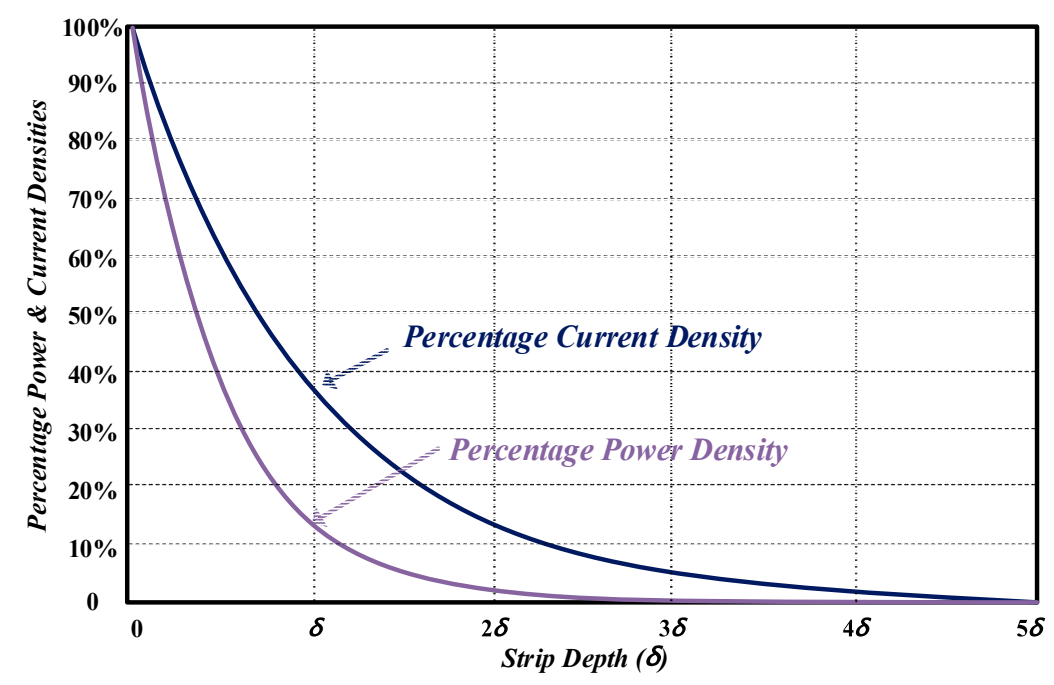

Figure 8. Parameter values of the Ti load based on frequency variation.
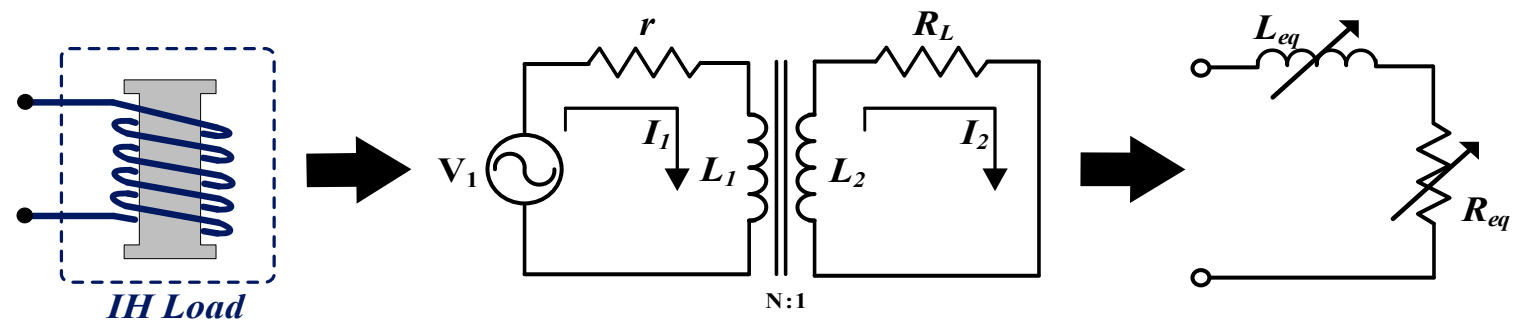

Figure 9. Equivalent circuit transformation of the induction heating (IH) system.

These equivalent parameters, $R_{e q}$ and $L_{e q}$, are dependent on the size of the heating object, the conductivity and permeability of the material, and the operating frequency. The transformer secondary resistance $R_{L}$, which can be regarded as the resistance component of the Ti cylinder, is determined using the $\delta$ value of the eddy current and is calculated as follows:

$$
R_{L}=R_{T i}=k \sqrt{\rho \mu_{r} 2 \pi f}, I_{2}=N I_{1}
$$

The graph in Figure 10 shows changes in the $R_{e q}$ and $L_{e q}$ of the proposed Ti load with frequency variation. Therefore, the output power generated by the actual $\mathrm{IH}$ cleaning system is given by the relationship between the resistance and current, as follows:

$$
P=k \cdot\left(N I_{1}\right)^{2} \cdot \sqrt{\rho \mu_{r} 2 \pi f}
$$


where $k$ and $N$ are constants that are related to the permeability and number of turns of the Ti load coil, respectively. Finally, the load current required to generate SHS is calculated using the heat capacity $Q_{\text {heat }}$ expressed in Equation (1).

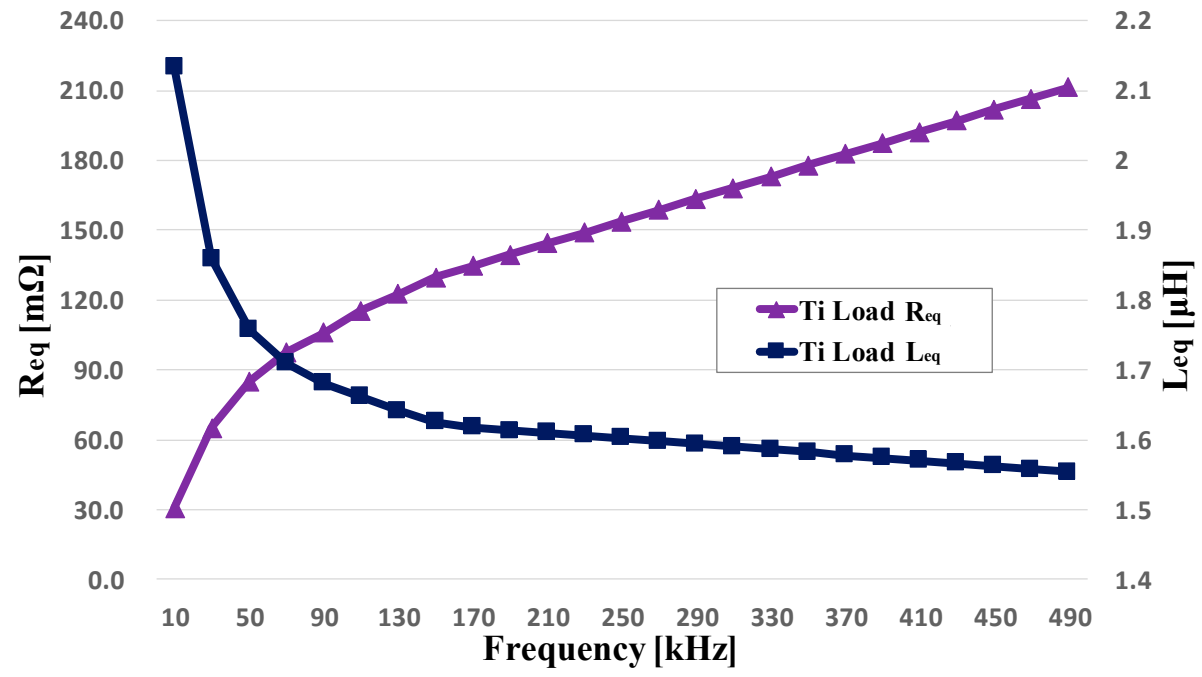

Figure 10. Parameter values of Ti load based on frequency variation.

\subsection{Design of Electric Power Converter Specifications and Simulation Verification}

Because the electric power converter for the IH-type cleaning device operates at a high frequency, it must be designed to operate with zero-voltage switching (ZVS) to minimize switching loss [35]. Furthermore, the large current flowing through the coil causes a burden on the electric power converter. Therefore, LCL topology was selected, as shown in Figure 11, to reduce the inverter current on the primary side [36,37].

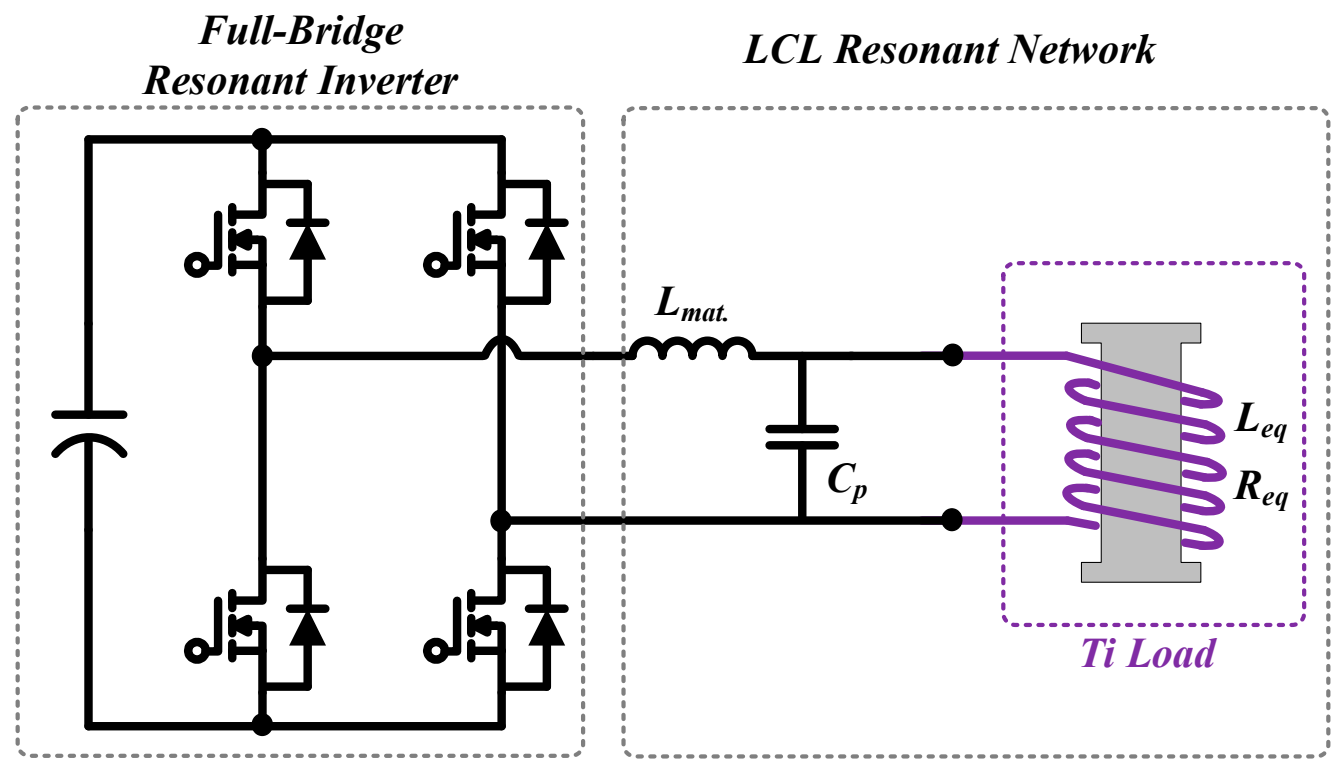

Figure 11. Ti load with LCL topology structure.

As described above, the LCL network topology consists of an inductor ( $L_{\text {mat. }}$ ) added for impedance matching, a parallel capacitor $\left(C_{p}\right)$, and a Ti load $\left(L_{e q}\right)$ at the output stage. Therefore, it is possible to filter the harmonic components through the added $L_{\text {mat. }}$ and $C_{p}$. In addition, there is an advantage of increasing the current in the coil of the load while reducing the current flowing through $L_{\text {mat. }}$. 
based on the resonance network design [38]. The third-order filter network of the LCL topology has characteristics of constant current (resonant frequency $=\omega_{r 1}$ ) and constant voltage (resonant frequency $\left.=\omega_{r 2}\right)[39,40]$. Each resonant frequency and quality $(Q)$ factor can be calculated as follows:

$$
\begin{gathered}
\omega_{r 1}=\frac{1}{\sqrt{L_{\text {mat. }} C_{p}}} \\
\omega_{r 2}=\frac{1}{\sqrt{\left(L_{\text {mat. }} \| L_{e q}\right) C_{p}}} \\
Q=\frac{\omega_{o} L}{R_{L}}=\frac{Z_{n}}{R_{L}}
\end{gathered}
$$

In addition, the input/output voltage gain equation according to $\gamma$, which is the ratio of $L_{m a t}$. and $L_{e q}$, is given by:

$$
\begin{gathered}
\gamma=\frac{L_{e q}}{L_{\text {mat. }}} \\
\frac{V_{\text {out }}}{V_{\text {in }}}=\frac{1}{\left(1-\omega_{n}^{2}\right)+j Q\left((1+\gamma) \omega_{n}-\gamma \omega_{n}^{3}\right)}
\end{gathered}
$$

Depending on the design of the inductance ratio $\gamma$, the LCL resonant network can be set to step up or step down output linearly. In addition, when designing $L_{m a t}$. for impedance matching in high power, air core coils are mainly used to prevent saturation and fluctuations in inductance values, depending on temperature. Moreover, operation at high frequencies requires film capacitors rated for high voltage and high currents of tens of hundreds of nanofarads. In addition, more accurate results can be obtained by considering the parasitic capacitance of the switch when designing the resonant network in operation at high frequencies and high voltages [41,42]. In general, the power control of the IH application with the LCL structure allows frequency control in the region higher than the $\omega_{r 2}$ resonance frequency, and the inverter switch operates in the region where ZVS is possible. The DC voltage gain curve of the LCL resonant network according to the variation of the $Q$-factor value can be expressed as shown in Figure 12. Table 2 shows the amount of power required to heat SHS at temperatures above $200{ }^{\circ} \mathrm{C}$ within $10 \mathrm{~s}$ when saturated steam at $133.25^{\circ} \mathrm{C}$ flows into the Ti load at a flow rate of $6 \mathrm{~L} / \mathrm{min}$ and a pressure of $3 \mathrm{~atm}$. Table 2 also lists the cleaning equipment specifications and resonant network parameters.

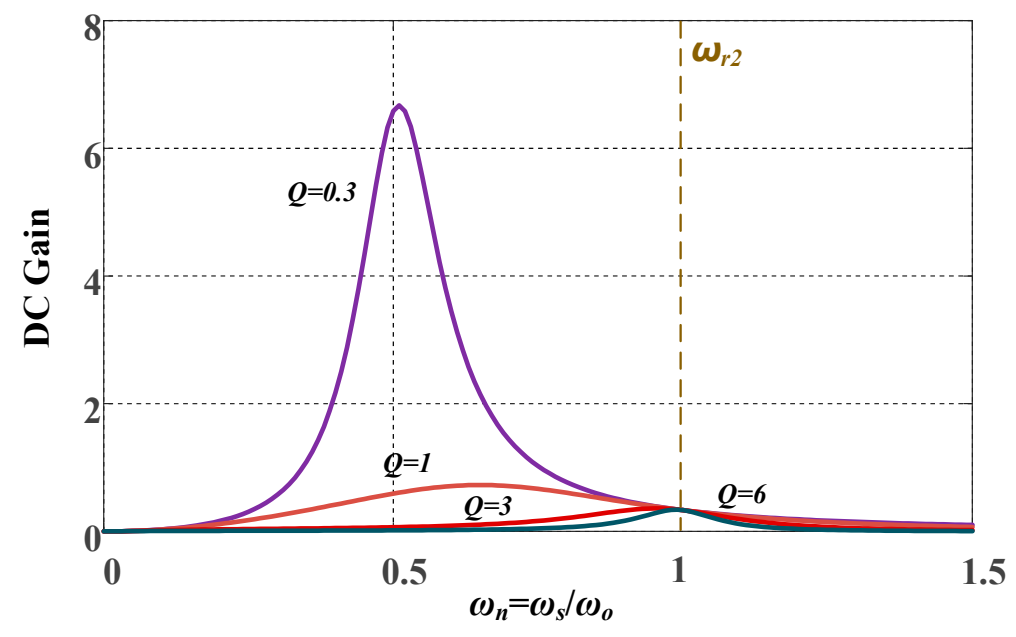

Figure 12. DC gain characteristics of the LCL resonant network. 
Table 2. Specifications of the cleaning equipment and resonant network parameters.

\begin{tabular}{cccc}
\hline \multicolumn{2}{c}{ Wafer Cleaning Equipment Spec. } & \multicolumn{2}{c}{ Resonant Network } \\
\hline Parameters & Value [Unit] & Parameters & Value [Unit] \\
\hline DC-link Voltage & $280[\mathrm{~V}]$ & Capacitance, $C_{p}$ & $100[\mathrm{nF}]$ \\
Input Steam Temp. & $133.25\left[{ }^{\circ} \mathrm{C}\right]$ & Primary Inductance, $L_{\text {mat. }}$ & $7.5[\mu \mathrm{H}]$ \\
Output Steam Temp. & $>200\left[{ }^{\circ} \mathrm{C}\right]$ & Secondary Inductance, $L_{e q}$ & $1.556[\mu \mathrm{H}]$ \\
Active Power & $2.2[\mathrm{~kW}]$ & Coil Resistance, $R_{e q}$ & $209.1[\mathrm{~m} \Omega]$ \\
Coil Current & $100\left[\mathrm{~A}_{\mathrm{rms}}\right]$ & Coil Conduit Size & $1 / 4[\mathrm{inch}]$ \\
Switching Frequency & $465[\mathrm{kHz}]$ & Coil Turns & $9[$ turn] \\
\hline
\end{tabular}

Figure 13 shows the simulation waveforms of the current and phase of the inverter and coil based on the variations in frequency and considering the parameter values. Figure 13a shows the inverter current and phase angle of the voltage and current. The inverter can operate with ZVS at a switching frequency of $465 \mathrm{kHz}$ and an inverter current of approximately $35 \mathrm{~A}_{\mathrm{rms}}$. Figure $13 \mathrm{~b}$ shows the coil current and phase angle of the voltage and current. The current of the coil is approximately $100 \mathrm{~A}_{\mathrm{rms}}$ at the operating frequency, and it can be confirmed that it is similar to the calculated active power.

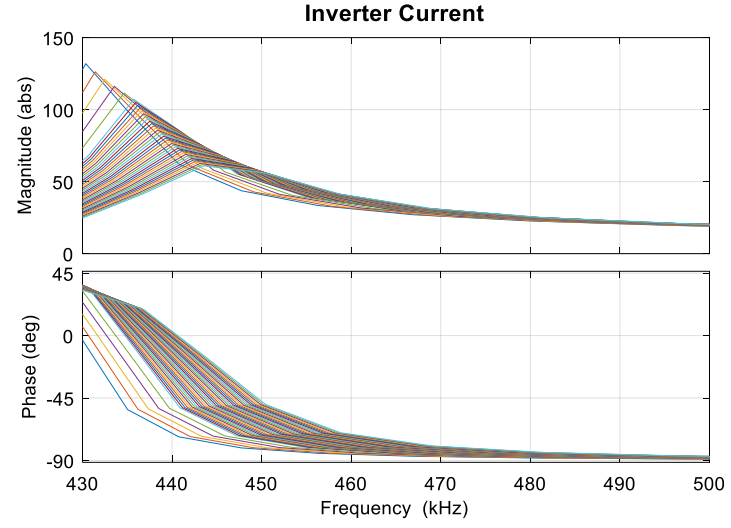

(a) Inverter current and phase

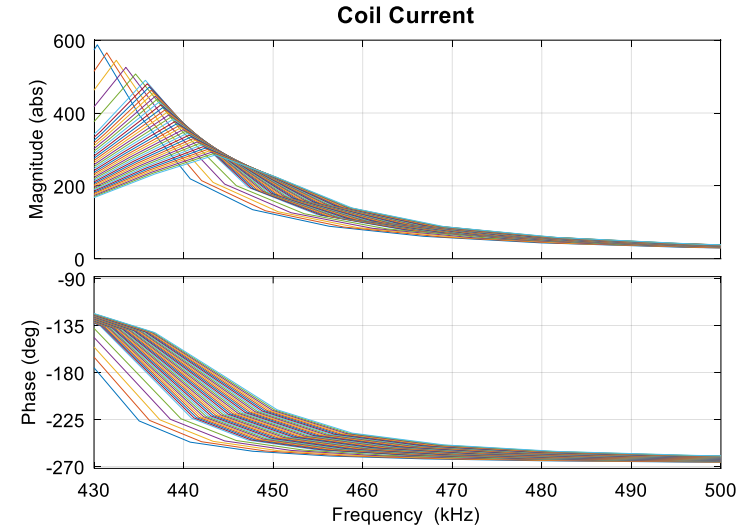

(b) Coil current and phase

Figure 13. Current and phase of inverter and coil with respect to frequency variation.

\section{Experimental Verification}

Experiments were performed using a $2.2 \mathrm{~kW}$ prototype to validate the proposed wafer cleaning $\mathrm{IH}$ system. Preliminary experiments were conducted to compare the heating performance of the proposed Ti load with the various Ti heating objects. Finally, an SHS generation experiment was performed on the cleaning equipment with the proposed Ti load.

\subsection{Preliminary Experiment Using a Water Chiller System}

Preliminary IH experiments were conducted using a water chiller system before generating the SHS, as shown in Figure 14. The experiment was carried out using a heated object made of Ti for four cases. The detailed experimental specifications and heating object conditions are presented in Table 3. The water to be passed through the Ti loads was cooled to $25^{\circ} \mathrm{C}$ and supplied, using the chiller system, at a flow rate of $9 \mathrm{~L} / \mathrm{min}$. Ti loads in all four cases were fitted with a load current of approximately $100 \mathrm{~A}_{\mathrm{rms}}$. Figure 15 shows the preliminary experimental results for each Ti load case. Case IV, which corresponds to the proposed Ti load, had the highest heating performance because of the IH property, which caused the outer surface of the heating body to be heated first. Case IV had a temperature rise rate $(\Delta T / \Delta t)$ that was more than 400 times higher than that of the other cases. 


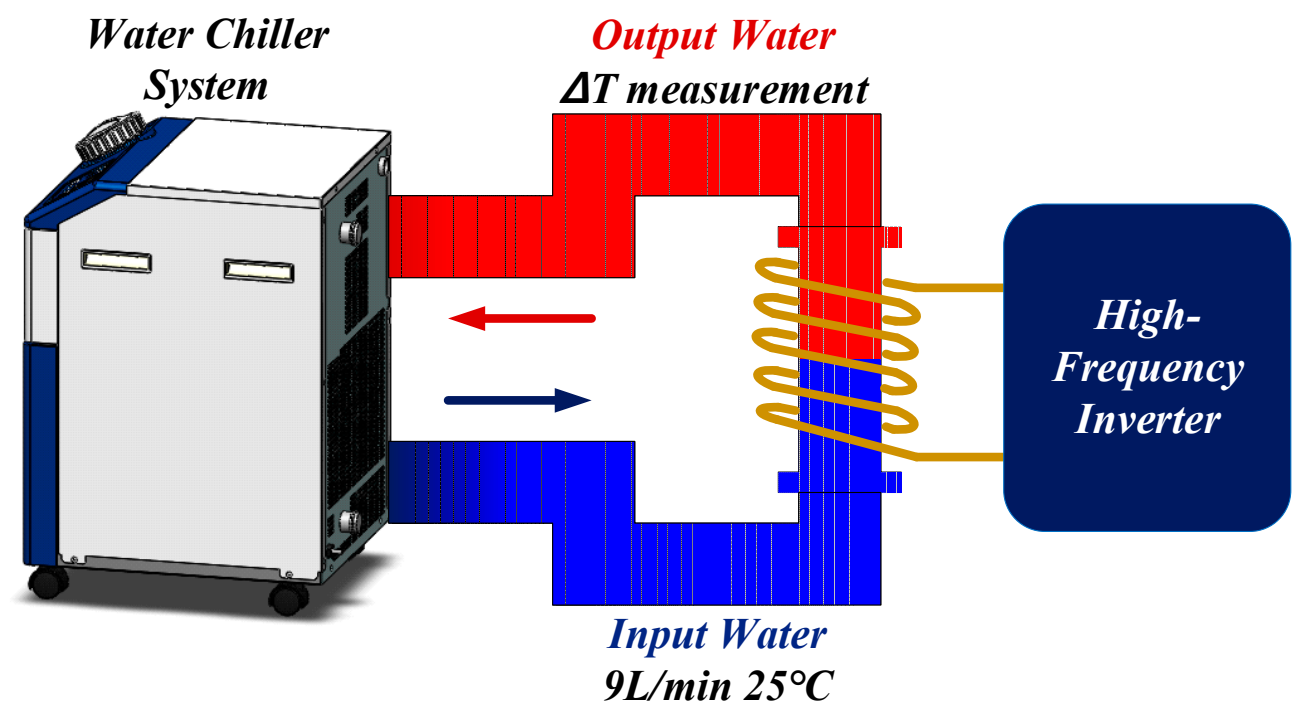

Figure 14. IH test bed with water chiller system.

Table 3. Experimental specifications of heating objects.

\begin{tabular}{ccccc}
\hline $\begin{array}{c}\text { Picture of Heating } \\
\text { Object }\end{array}$ & & & III & IV \\
\hline Case & $\mathbf{I}$ & $452[\mathrm{kHz}]$ & $480[\mathrm{kHz}]$ & $465[\mathrm{kHz}]$ \\
Frequency & $435[\mathrm{kHz}]$ & $99.2\left[\mathrm{~A}_{\mathrm{rms}}\right]$ & $98.3\left[\mathrm{~A}_{\mathrm{rms}}\right]$ & $99.9\left[\mathrm{~A}_{\mathrm{rms}}\right]$ \\
Current & $99.3\left[\mathrm{~A}_{\mathrm{rms}}\right]$ & $343[\mathrm{~s}]$ & $343[\mathrm{~s}]$ & $4[\mathrm{~s}]$ \\
Heating time & $343[\mathrm{~s}]$ & $43.4\left[{ }^{\circ} \mathrm{C}\right]$ & $37.8\left[{ }^{\circ} \mathrm{C}\right]$ & $99.2\left[{ }^{\circ} \mathrm{C}\right]$ \\
Max. temperature & $36.3\left[{ }^{\circ} \mathrm{C}\right]$ & $0.05\left[{ }^{\circ} \mathrm{C} / \mathrm{s}\right]$ & $0.04\left[{ }^{\circ} \mathrm{C} / \mathrm{s}\right]$ & $18.55\left[{ }^{\circ} \mathrm{C} / \mathrm{s}\right]$ \\
\hline$T / \Delta t$ & $0.03\left[{ }^{\circ} \mathrm{C} / \mathrm{s}\right]$ & &
\end{tabular}

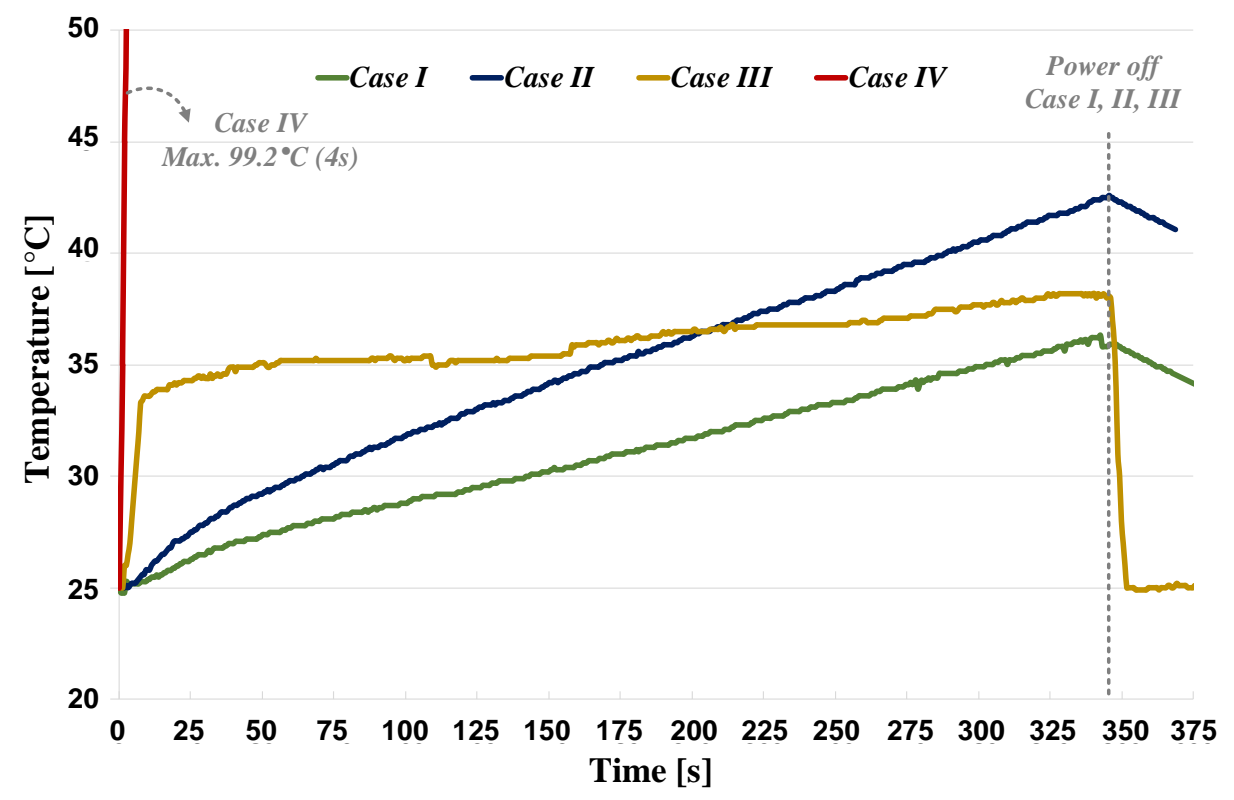

Figure 15. Experimental results of temperature rise for each Ti load case. 


\subsection{SHS Generation Heating Test Bed}

A test bed was constructed using $2.2 \mathrm{~kW}$ wafer cleaning equipment, as shown in Figure 16, to verify the SHS heating performance of the proposed system. The test conditions were as follows:

1. Saturated steam that was heated to generate SHS, supplied by preheating the water using a quartz heater.

2. The instantaneous input and output steam temperatures of the Ti load were measured using a k-type thermocouple (TC).

3. The copper tubing coil of the Ti load and inverter switch were water-cooled using the chiller system.

4. The time at which the high-temperature pure SHS to be used in the wafer cleaning process was generated by IH was measured.

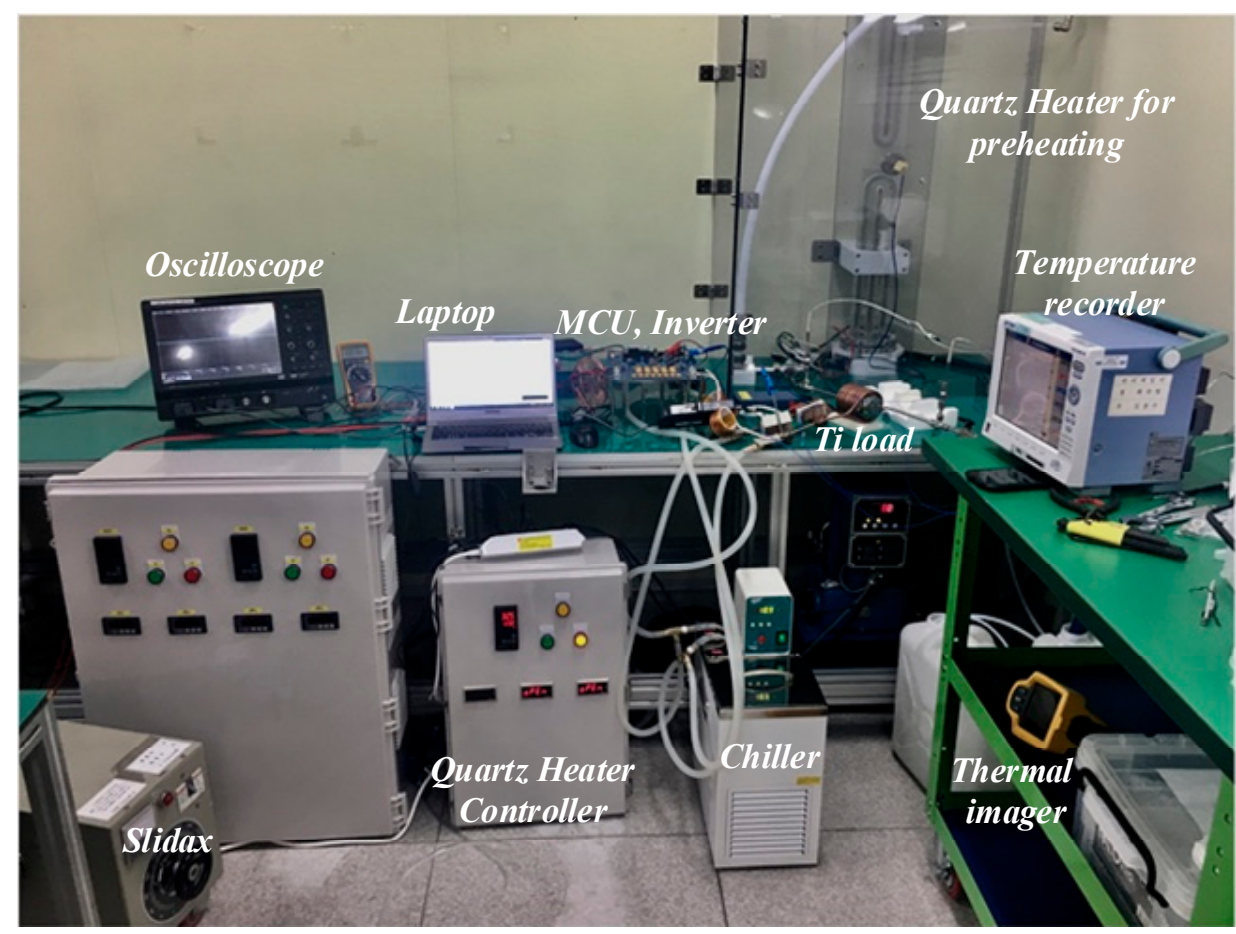

Figure 16. Test bed for SHS generation.

\subsection{Experimental Results}

Figure 17 shows the voltage and current waveforms of the inverters and coils of the wafer cleaning equipment. The experimental waveform showed that the inverter operated with ZVS. The coil current was $99.93 \mathrm{~A}_{\mathrm{rms}}$ and the coil voltage was $443.7 \mathrm{~V}_{\mathrm{rms}}$ at a switching frequency of $482 \mathrm{kHz}$. The inverter current was $31.61 \mathrm{~A}_{\mathrm{rms}}$, apparent power was $45.4 \mathrm{kVA}$, and active power was $2.15 \mathrm{~kW}$. The experimental waveform shows results that are similar to those obtained from mathematical calculations and simulations.

Figure 18 plots the internal and external temperatures of the Ti load and the input and output temperatures of the flowing steam measured using the TC; in this figure, the red line represents the SHS temperature, which is the steam output from the proposed cleaning equipment. In addition, Table 4 shows the temperature values measured at $10 \mathrm{~s}$ intervals during the heating experiment performed with an SHS generator. When the inverter was operated with saturated steam supplied from the quartz heater, SHS with a temperature higher than $200^{\circ} \mathrm{C}$ was generated in $10 \mathrm{~s}$. After approximately $1 \mathrm{~min}$, the SHS reached a temperature of $400^{\circ} \mathrm{C}$, and the modulated set temperature of the SHS could be controlled in order to perform TFT-LCD and wafer cleaning at the required temperature. 


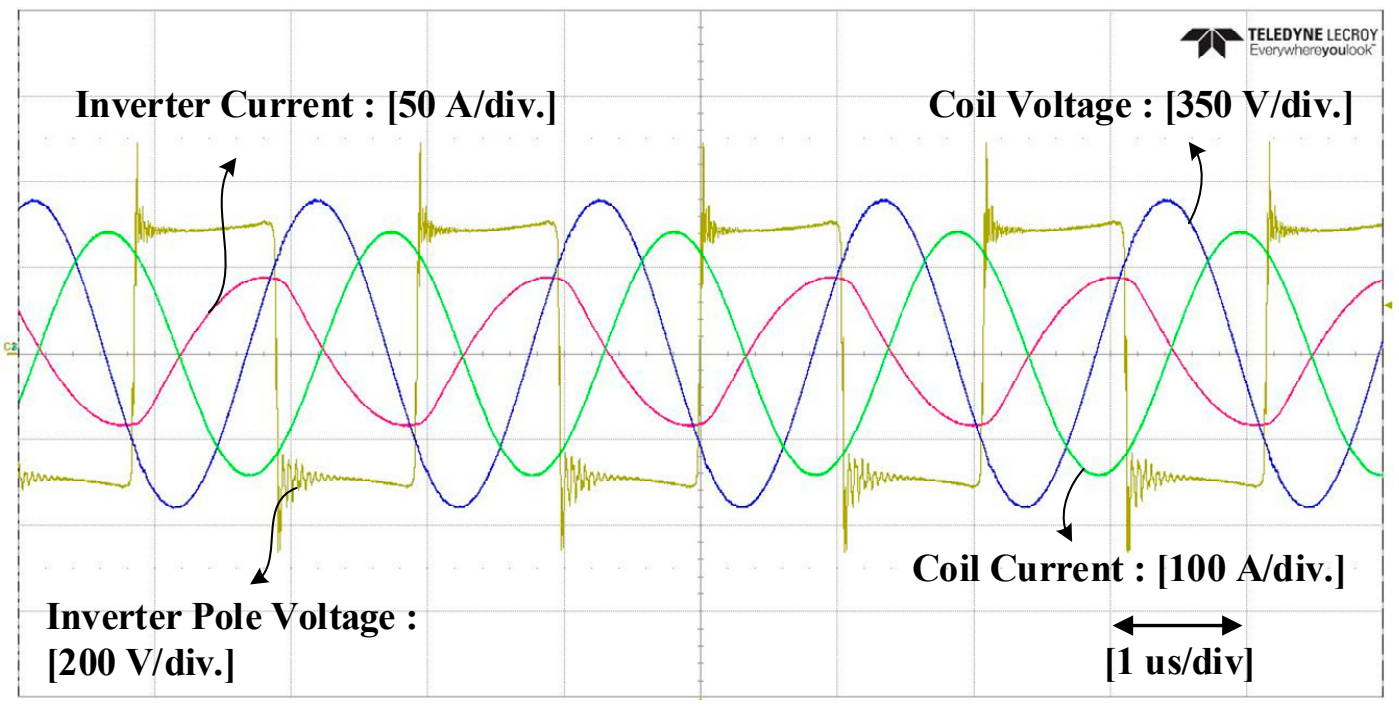

Figure 17. Experimental waveforms of the wafer cleaning equipment.

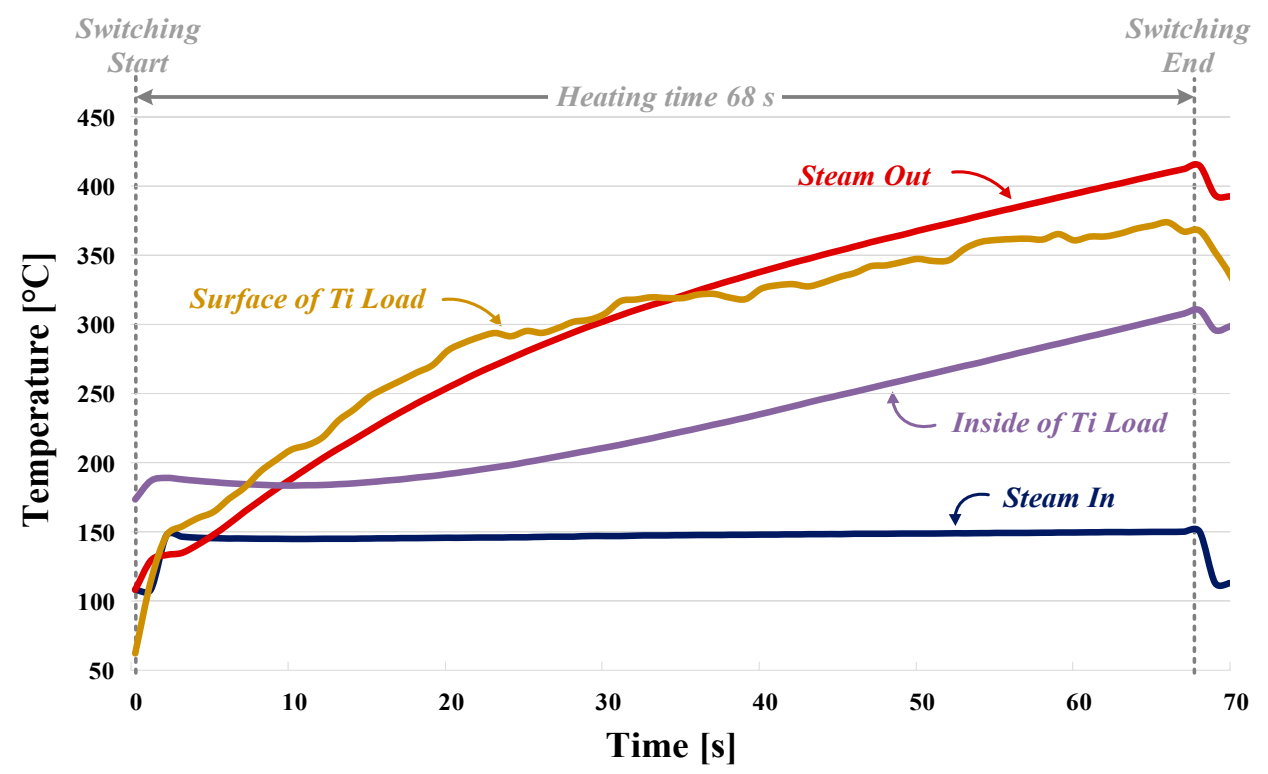

Figure 18. Temperature graph of the steam heating test.

Table 4. Temperature results of the steam heating test.

\begin{tabular}{|c|c|c|c|c|c|c|}
\hline \multirow{2}{*}{ Case } & \multicolumn{6}{|c|}{ Heating Time } \\
\hline & $10[s]$ & $20[s]$ & $30[s]$ & $40[s]$ & $50[s]$ & $60[s]$ \\
\hline Inside of $\mathrm{Ti}$ load & $183.6\left[{ }^{\circ} \mathrm{C}\right]$ & $191.9\left[{ }^{\circ} \mathrm{C}\right]$ & $211.1\left[{ }^{\circ} \mathrm{C}\right]$ & $235.3\left[{ }^{\circ} \mathrm{C}\right]$ & $262.2\left[{ }^{\circ} \mathrm{C}\right]$ & $288.9\left[{ }^{\circ} \mathrm{C}\right]$ \\
\hline Surface of Ti load & $209.3\left[{ }^{\circ} \mathrm{C}\right]$ & $281.2\left[{ }^{\circ} \mathrm{C}\right]$ & $307.8\left[{ }^{\circ} \mathrm{C}\right]$ & $326.1\left[{ }^{\circ} \mathrm{C}\right]$ & $347.5\left[{ }^{\circ} \mathrm{C}\right]$ & $363.7\left[{ }^{\circ} \mathrm{C}\right]$ \\
\hline Steam in & $144.8\left[{ }^{\circ} \mathrm{C}\right]$ & $145.6\left[{ }^{\circ} \mathrm{C}\right]$ & $146.9\left[{ }^{\circ} \mathrm{C}\right]$ & $147.9\left[{ }^{\circ} \mathrm{C}\right]$ & $148.7\left[{ }^{\circ} \mathrm{C}\right]$ & $149.5\left[{ }^{\circ} \mathrm{C}\right]$ \\
\hline Steam out & $201.2\left[{ }^{\circ} \mathrm{C}\right]$ & $262.9\left[{ }^{\circ} \mathrm{C}\right]$ & $310.7\left[{ }^{\circ} \mathrm{C}\right]$ & $344.5\left[{ }^{\circ} \mathrm{C}\right]$ & $370.8\left[{ }^{\circ} \mathrm{C}\right]$ & $400.1\left[{ }^{\circ} \mathrm{C}\right]$ \\
\hline
\end{tabular}

\section{Conclusions}

In this study, cleaning equipment with a capacity of $2.2 \mathrm{~kW}$ was designed and fabricated using pure Ti to clean work pieces such as semiconductor wafers. Enthalpy steam characteristics were analyzed to perform the cleaning process with an eco-friendly method using SHS. IH was employed to rapidly and efficiently generate SHS with a high temperature and pressure. A heating object with a 
structure in which the inner fluid path was made of pure Ti and the fluid could stay within a limited length for a long time was proposed. The output power of the cleaning equipment for generating SHS was derived based on mathematical calculations and simulations. In order to effectively increase the current flowing through the coil used for IH, the LCL resonance network was applied to the proposed power converter, and the parameter values were analyzed. The steam heating performance of the proposed cleaning equipment was verified by the experimental results, which demonstrate that the designed cleaning equipment generates SHS with a temperature of $200{ }^{\circ} \mathrm{C}$ in $10 \mathrm{~s}$ and that the SHS reaches $400{ }^{\circ} \mathrm{C}$ after $60 \mathrm{~s}$. The proposed cleaning system can contribute to the successful commercialization of wafer cleaning by satisfying the requirements of wafer cleaning processes.

Author Contributions: Conceptualization, S.M.P. and J.-H.C.; Data curation, S.M.P., E.J., J.-H.K. and J.-H.C.; Formal analysis, E.J. and J.S.P.; Investigation, J.-H.K. and J.-H.C.; Project administration, B.K.L.; Software, S.M.P. and J.-H.K.; Supervision, J.-H.C. and B.K.L.; Validation, E.J. and J.S.P.; Visualization, E.J. and J.-H.K.; Writing-original draft, S.M.P. and B.K.L.; Writing-review \& editing, S.M.P., J.S.P. and B.K.L. All authors have read and agreed to the published version of the manuscript.

Funding: This work was supported by the Korea Institute of Energy Technology Evaluation and Planning (KETEP) and the Ministry of Trade, Industry and Energy (MOTIE) of the Republic of Korea (No. 2018201010650A and No. 20192010106690).

Conflicts of Interest: The authors declare no conflict of interest.

\section{References}

1. Samadi, H.; Pfeffer, M.; Altmann, R.; Leibold, A.; Gumprecht, T.; Bauer, A. Particle free handling of substrates. IEEE Trans. Semicond. Manuf. 2016, 29, 314-319. [CrossRef]

2. Lee, J.S.; Jun, P.K.; Lim, H.B. Determination of Metal Contaminants Using Automated In-Situ Metrology in Semiconductor Cleaning Process. IEEE Sens. J. 2011, 11, 1120-1128. [CrossRef]

3. Nagai, M. Substrate Cleaning Methods for Fabricating OLEDs and Its Effect on Current Leakage Defect Formation. J. Disp. Technol. 2009, 5, 126-132. [CrossRef]

4. Cui, W.; Liu, W.; Wang, T.; Ma, C. The Application of Atmospheric Pressure Dielectric Barrier Discharge Plasma on the Cleaning of Photovoltaic Panels. IEEE Trans. Plasma Sci. 2017, 45, 328-335. [CrossRef]

5. Mitsumori, K.; Nobuaki, H.; Takahashi, N.; Imaoka, T.; Ohmi, T. Advanced wet cleaning using novel nozzle and functional ultrapure water in next generation FPD/LSI manufacturing. In Proceedings of the ISSM2000. Ninth International Symposium on Semiconductor Manufacturing (IEEE Cat. No.00CH37130), Tokyo, Japan, 26 September 2000; pp. 329-332.

6. Ward, P.P. Ultra-fast plasma cleaning as a waste minimization tool and some applications in environmentally conscious manufacturing. In Proceedings of the International Conference on Plasma Science (Papers in Summary from Only Received), Madison, WI, USA, 5-8 June 1995; p. 268.

7. Sahari, S.K.; Fathi, N.A.F.N.Z.; Sutan, N.M.; Sapawi, R.; Hamzah, A.A.b.; Majlis, B.Y. Wet chemical cleaning effect on the formation of ultrathin interfacial layer between Germanium (Ge) and high-k dielectric. In Proceedings of the 2015 IEEE Regional Symposium on Micro and Nanoelectronics (RSM), Kuala, Terengganu, 19-21 August 2015; pp. 1-3.

8. Hu, S.; Shiue, A.; Tseng, W.; Leggett, G. Perfluorocompound Emissions Control and Kinetic Characteristics in Point-of-Use Wet-Thermal-Wet Abatement of Plasma-Enhanced Chemical Vapor Deposition Chamber Cleaning. IEEE Trans. Semicond. Manuf. 2018, 31, 302-308. [CrossRef]

9. Dragonas, F.A.; Neretti, G.; Sanjeevikumar, P.; Grandi, G. High-Voltage High-Frequency Arbitrary Waveform Multilevel Generator for DBD Plasma Actuators. IEEE Trans. Ind. Appl. 2015, 51, 3334-3342. [CrossRef]

10. Liu, H.; Tang, Z.; Yang, K.; Zhang, Y.; Li, H.; Zhu, X. Optical Properties of Arc Spot Plasma for Cleaning Oxide on the Steel Surface. IEEE Trans. Plasma Sci. 2018, 46, 2916-2919. [CrossRef]

11. Liu, C.; Nishida, Y.; Iwasaki, K.; Sung, W.; Wu, F. Characteristics of DC or Pulsed-Type High-Electric Field Plasma and its Application to Air Cleaning System. IEEE Trans. Plasma Sci. 2019, 47, 1121-1128. [CrossRef]

12. Jun, Z.; Fei, Y.X.; Hailin, S. A highly reliable cleaning process. In Proceedings of the International Conference on Electronic Packaging Technology (ICEPT), Shanghai, China, 8-11 August 2018; pp. 834-839.

13. Nakata, K.; Fukui, T.; Nagai, T. Particle Adsorption onto Si-Based Wafers in Ultrapure Water; Its Mechanism and Effect of Carbon Dioxide. IEEE Trans. Semicond. Manuf. 2017, 30, 371-376. [CrossRef] 
14. Ukai, Y. TFT-LCD manufacturing technology-Current status and future prospect. In Proceedings of the 2007 International Workshop on Physics of Semiconductor Devices, Mumbai, India, 16-20 December 2007; pp. 29-34.

15. Liu, Y.; Zhou, C.; Xiang, W. DE Algorithm Fuzzy Control of Super-Heated Steam Temperature. In Proceedings of the 20169th International Symposium on Computational Intelligence and Design (ISCID), Hangzhou, China, 10-11 December 2016; pp. 282-285.

16. Zhao, W.J.; Niu, Y.U.; Liu, J.Z. Multi-model adaptive control for the superheated steam temperature. In Proceedings of the International Conference on Machine Learning and Cybernetics, Beijing, China, 4-5 November 2002; Volume 1, pp. 269-272.

17. Kazarinov, L.S.; Shnayder, D.A.; Kolesnikova, O.V. Heat load control in steam boilers. In Proceedings of the 2017 International Conference on Industrial Engineering, Applications and Manufacturing (ICIEAM), St. Petersburg, Russia, 16-19 May 2017; pp. 1-4.

18. Liplavk, V.M.; Bikbulatov, R.K.; Zyryanov, V.P. Experience and trends in automation of the burning process in steam boilers of Ufa Thermal Power Plants. Electr. Pow. Plants 2011, 3, 16-23.

19. Han, Z.; He, R.; Xu, Y. Effect of steam pressure fluctuation in turbine steam pipe on stability of power system. In Proceedings of the 2008 Third International Conference on Electric Utility Deregulation and Restructuring and Power Technologies, Nanjing, China, 6-9 April 2008; pp. 1127-1131.

20. Wei, L.; Fang, F. A novel IMC cascade control structure of super-heated steam temperature system for super-critical coal-fired boilers. In Proceedings of the 2011 Chinese Control and Decision Conference (CCDC), Mianyang, China, 23-25 May 2011; pp. 641-645.

21. Jin, X.; Sun, J.; Liu, J.; Zhang, L. Design of adaptive internal model for main steam temperature control system based on single neuron. In Proceedings of the Fifth World Congress on Intelligent Control and Automation (IEEE Cat. No. 04EX788), Hangzhou, China, 15-19 June 2004; Volume 4, pp. 3560-3564.

22. Wang, Q.; Yao, J.; Wang, J. Genetic-Based Active Disturbance Rejection Controller for Super-Heated Steam Temperature Regulation. In Proceedings of the Second International Conference on Genetic and Evolutionary Computing, Jingzhou, China, 25-26 September 2008; pp. 101-104.

23. Jeong, S.; Park, H.; Jung, J. Design Methodology of 3 kW Induction Heating System for both Low Resistance and High Resistance Containers in a Single Burner. In Proceedings of the 2018 International Power Electronics Conference (IPEC-Niigata 2018 -ECCE Asia), Niigata, Japan, 20-24 May 2018; pp. 289-295.

24. Wesołowski, M. Induction heating of thin aluminum layers during depolymerization process. In Proceedings of the 2017 Progress in Applied Electrical Engineering (PAEE), Koscielisko, Poland, 25-30 June 2017; pp. 1-4.

25. Phadungthin, R.; Haema, J. Full bridge resonant inverter for non-ferrous metal induction heating application. In Proceedings of the 2015 IEEE PES Asia-Pacific Power and Energy Engineering Conference (APPEEC), Brisbane, QLD, Australia, 15-18 November 2015.

26. Tomita, H.; Maruyama, T.; Yoshimura, S.; Takahashi, N. Superheated steam generator by induction heating. In Proceedings of the 2009 13th European Conference on Power Electronics and Applications, Barcelona, Spain, 8-10 September 2009; pp. 1-4.

27. Makimura, Y.; Tomita, H.; Motegi, S. Improvement of superheated steam generator by induction heating. In Proceedings of the 2010 International Conference on Computer Applications and Industrial Electronics, Kuala Lumpur, Malaysia, 5-8 December 2010; pp. 615-618.

28. Muhammad, Z.; Rahiman, M.H.F.; Taib, M.N. Characteristic of steam distillation pot with induction heating system based on step test response. In Proceedings of the 2011 IEEE Control and System Graduate Research Colloquium, Shah Alam, Malaysia, 27-28 June 2011; pp. 98-102.

29. Makulov, I.A.; Alitdinov, A.E. The equipment and application features of induction heating in oil and gas industry. In Proceedings of the 2017 International Conference on Industrial Engineering, Applications and Manufacturing (ICIEAM), St. Petersburg, Russia, 16-19 May 2017; pp. 1-4.

30. Zhu, T.; Feng, P.; Li, X.; Li, F.; Rong, Y. The Study of the Effect of Magnetic Flux Concentrator to the Induction Heating System Using Coupled Electromagnetic-Thermal Simulation Model. In Proceedings of the 2013 International Conference on Mechanical and Automation Engineering, Jiujang, China, 21-23 July 2013; pp. 123-127.

31. Cho, K.H. Coupled electro-magneto-thermal model for induction heating process of a moving billet. Int. J. Therm. Sci. 2012, 60, 195-204. [CrossRef] 
32. Kim, D.; So, J.; Kim, D. Study on Heating Performance Improvement of Practical Induction Heating Rice Cooker with Magnetic Flux Concentrator. IEEE Trans. Appl. Supercond. 2016, 26, 1-4. [CrossRef]

33. Han, W.; Chau, K.T.; Jiang, C.; Liu, W. All-Metal Domestic Induction Heating Using Single-Frequency Double-Layer Coils. IEEE Trans. Magn. 2018, 54, 1-5.

34. Han, W.; Chau, K.T.; Zhang, Z. Flexible induction heating using magnetic resonant coupling. IEEE Trans. Ind. Electron. 2017, 64, 1982-1992. [CrossRef]

35. Mollov, S.V.; Theodoridis, M.; Forsyth, A.J. High frequency voltage-fed inverter with phase-shift control for induction heating. IEE Proc. Electr. Power Appl. 2004, 151, 12-18. [CrossRef]

36. Park, T.J.; Kim, T.W.; Han, M.H. Load estimation and effective heating method of LCL-resonant inductive heater. In Proceedings of the 8th International Conference on Power Electronics ECCE Asia, Jeju, Korea, 30 May-3 June 2011; pp. 1576-1578.

37. Yoo, H.; Shim, E.; Kang, J.; Choi, G.; Lee, C.; Bang, B. 100 kHz IGBT inverter use of LCL topology for high power induction heating. In Proceedings of the 8th International Conference on Power Electronics ECCE Asia, Jeju, Korea, 30 May-3 June 2011; pp. 1572-1575.

38. Dzieniakowski, M.A. LCL topology variability in the VSI-LCL induction heating system. In Proceedings of the 2014 16th European Conference on Power Electronics and Applications, Lappeenranta, Finland, 26-28 August 2014; pp. 1-7.

39. Dzieniakowski, M.A.; Fabianowski, J.; Ibach, R. LCL-load modular converter for induction heating. In Proceedings of the 2008 IEEE Power Electronics and Motion Control Conference. (EPE/PEMC), Poznan, Poland, 1-3 September 2008; pp. 2082-2086.

40. Espi-Huerta, J.M.; Santamaria, E.J.D.G.; Gil, R.G.; Castello-Moreno, J. Design of the L-LC Resonant Inverter for Induction Heating Based on Its Equivalent SRI. IEEE Trans. Ind. Electron. 2007, 54, 3178-3187. [CrossRef]

41. Deng, L.; Wang, P.; Li, X.; Xiao, H.; Peng, T. Investigation on the Parasitic Capacitance of High Frequency and High Voltage Transformers of Multi-Section Windings. IEEE Access 2020, 8, 14065-14073. [CrossRef]

42. Borage, M.; Nagesh, K.V.; Bhatia, M.S.; Tiwari, S. Design of LCL-T Resonant Converter Including the Effect of Transformer Winding Capacitance. IEEE Trans. Ind. Electron. 2009, 56, 1420-1427. [CrossRef]

Publisher's Note: MDPI stays neutral with regard to jurisdictional claims in published maps and institutional affiliations.

(C) 2020 by the authors. Licensee MDPI, Basel, Switzerland. This article is an open access article distributed under the terms and conditions of the Creative Commons Attribution (CC BY) license (http://creativecommons.org/licenses/by/4.0/). 